United States

\title{
NAS calls for global aerosol ban
}

An international ban on non-essential uses of chlorofluorocarbon (CFC) aerosol propellants is now the most effective way to reduce the dangers to health and food supplies from further depletion of the ozone layer - says a report published by the National Academy of Sciences. David Dickson reports.

THE US banned aerosol spray cans a year ago, and this has led to a $50 \%$ drop in the use of CFCs.

The report points out that there remain many other uses of CFCs - for example in automobile air conditioning units, or in the production of flexible plastic foam cushioning - equally in need of control. Such non-propellant emissions could bring the total CFC emissions back up to previous levels within seven to ten years.

Reducing such uses, however, is likely to be difficult, since in many cases there are no acceptable substitutes. But the report points out that progress could be achieved if other industrialised nations would agree to a ban on non-essential aerosols: "should all countries decide to take action comparable with that already taken by the United States and Sweden, between one third and one half of the world's present $\mathrm{CFC}$ released would be avoided.

"Such a reduction would be a great step forward in decreasing the threat to the world's food supply, even though the magnitude of this threat is uncertain, and its advantages would far outweigh the relatively small costs of substituting alternative propellants and devices."

The report was prepared by the Committee on Impacts of Stratospheric Change and the Committee on Alternatives for the Reduction of Chlorofluorocarbon Emissions of the Academy's National Research Council. It was commissioned by the US Environmental Protection Agency.

Its strong message adds further fuel to the controversies that have been building up in other industrialised countries since the hypothesis that CFC emissions could seriously deplete the ozone layer subsequently increasing the exposure of humans, animals and plant-life to harmful ultra-violet radiation - was first raised by US scientists in 1974.

Two months ago, another academy committee confirmed earlier conclusions that, if emissions continue at the present rate, the amount of ozone in the atmosphere is likely ultimately to be depleted by about $16 \%$, half taking place within the next 30 years.

A few countries, in particular Sweden and Norway (expected soon to be joined by Canada) have agreed to follow the US example. But West Germany, France, the UK, Japan and Italy (who, together with the US, account for $90 \%$ of the West's production of CFCs) have refused to impose stringent controls.

There are signs that their position may be shifting. Member countries of the European Economic Community, for example, which earlier this year agreed voluntarily to reduce non-essential aerosol usage by $30 \%$ by 1982 , last week agreed to advance the date by six months, and to hold back on additional investment in industrial uses of CFCs.

The US however, would like things to move much faster. The report recommends the complete elimination of non-essential aerosols on a global basis. Dr John W Tukey, of Bell Laboratories, chairman of one of the panels, said last week: "The US has done it, and it wasn't very painful."

The new report examines in detail some of the consequences of the depletion in the ozone layer predicted by the companion alternative technologies, such as sealed air conditioning units, that might reduce or replace CFC-emitting processes.

The most obvious human health effect, it says, would be a further increase in skin cancer, (melanoma), already one of the most rapidly increasing forms of cancer in the US. The report predicts several thousand more cases of melanoma a year,

\section{Heavy water reactors are} less proliferation resistant Although making more efficient use of uranium, heavy water reactors are less proliferation resistant than either high temperature gas-cooled reactors or lightwater reactors, according to the draft report of the US Department of Energy's Non-Proliferation Alternative Systems Assessment Programme. The report, published last week in Washington for public comment, suggests that AGRs might have an application in the industrial process-heat market. In general, however, risks of proliferation by pushing ahead with the development of LWRs, and with liquid-metal fast breeder reactors. "In order to influence the liquid-metal fast breeder reactor programs of other countries, not only must the US be a member of the fast-breeder development community, but it also needs to exercise leadership in developing the technological measures which would reduce the poliferation risk of fast breeder reactors," the report says. study. And it discusses some of the it suggests that the US can minimise the "of which a substantial fraction would be fatal."

But the committee expresses greatest concern over the effect on global food supplies. "Here we know enough to be concerned, but not enough to predict what the biological effects would be," says Dr Tukey.

As DNA is affected by exposure to solar ultra-violet radiation the effect on the growth and reproduction of animals and plants would be expected to lower the yields of farms and fisheries.

Experiments indicate that some crops, such as sugar beets, tomatoes and corn, might be "significantly affected" by a $16 \%$ ozone depletion.

The report points to the particular threat to aquatic food systems studies of the UV sensitivity of young anchovies indicate that this commercially-important food source now lives near the limit of its solar-UV tolerance when at the surface of the water, as do certain crab and shrimp larva. "A $16 \%$ reduction in ozone concentration would be distinctly harmful to them in a surface location," it says.

Discussing the non-aerosol uses of CFCS, the report says that in many cases alternative technologies already exist, in particular for the agents used in blowing flexible pastic foam, and for the solvents used for cleaning metal or for sterilising medical supplies.

In other cases, however, controlling the use of CFCS is not likely to be so simple. It picks out their use in automobile air conditioning systems, the larges single sources of CFCS remaining in the US.

The prospects of reducing emissions from this source are "not good", though modifications to minimise leakage could yield significant reductions without burdensome costs.

The report outlines a variety of measures to restrict non-aerosol uses, from a complete ban on certain applications - the simplest approach, but "not always advantageous" - to a judicious mixture of tax measures, quotas on specific uses, and public edcuation.

The ozone problem differs from earlier environmental threats, since wherever CFCs are emitted, the ultimate effect is global. It is therefore the forerunner of another serious problem: the increased atmospheric concentration of carbon dioxide. It concludes: "the nations of the world collectively need to devise mechanisms for dealing with problems of this sort, assessing the scientific evidence as it develops and finding ways to agree on effective control actions, since these are not problems that can be adequately dealt with by the actions of only a few nations." 